\title{
Thermal response of energy soldier pile walls
}

\author{
Yu Zhong ${ }^{1}$, Guillermo Narsilio ${ }^{1, *}$, Nikolas Makasis ${ }^{1}$, Zhangshun $\mathrm{Li}^{1}$, and Gregorious Aditya ${ }^{1}$ \\ ${ }^{1}$ Department of Infrastructure Engineering, The University of Melbourne, Melbourne, Australia
}

\begin{abstract}
Utilising foundation systems as heat exchangers has received significant public interest worldwide, as these energy geo-structures can constitute a clean, renewable, and economical solution for space heating and cooling. Despite their potential, the thermal performance of energy retaining walls, especially soldier pile walls, has not been sufficiently studied and understood and thus further research is required. This work utilises the first ever energy soldier pile wall in the currently underconstruction Melbourne CBD North metro station as a case study. A section of this wall has been instrumented and monitored by the University of Melbourne. Full scale thermal response tests (TRTs) have been conducted on a single thermo-active soldier pile at two different excavation levels. Thermal response testing field data results are presented in terms of mean fluid temperatures and further analysed to show the potential impact of the excavation level on the structure's thermal performance. To further explore this impact of excavation depth (or pile embedment depth) and the long-term thermal performance of energy pile walls, a detailed 3D finite element numerical model is developed in COMSOL Multiphysics and validated against the field-testing results. The simulation suggests that thermally activating all the soldier piles in the station can provide enough energy to fulfil the heating and cooling demand of the station and to satisfy partial heating demand to the surrounding buildings. Furthermore, results suggest that current energy pile design approaches may be adapted for designing energy pile walls.
\end{abstract}

\section{Introduction}

Energy geo-structures are considered as innovative alternatives of traditional Ground Source Heat Pump (GSHP) systems for space heating and cooling, having the potential to reduce the upfront cost of the GSHP systems, which has rendered them increasingly popular [1-3]. These structures incorporate Ground Heat Exchangers (GHEs) into ground structures such as piles, retaining walls, tunnel linings and pavements that are required already for structural purposes, to integrate thermal energy provision as a secondary function. The most common type of energy geo-structures are energy piles, most likely due to their significant geometrical similarities with the thoroughly studied traditional vertical boreholes systems, attempting to adapt that the available thermal design methods for the traditional borehole systems for energy pile design. Moreover, a number of full-scale testing and monitoring data for energy piles have been well documented, providing key insights on assessing their thermal performance and establishing important databases for estimating relevant parameters and validating numerical models.

Much less information exists on energy pile walls, a type of energy retaining walls, compared to energy piles, even though both systems can be constructed in a similar manner and could adopt a similar design. A notable difference between energy piles and energy pile walls, however, is the fact that that the latter systems are not fully surrounded by the ground throughout their depths. This introduced excavation space can be a very significant factor affecting the thermal performance of the energy walls since it can both limit the available thermal storage as well as can introduce an underground space through which heat transfer needs to be carefully assessed [4]. Therefore, it is worth investigating the influence of the embedment depth and the sensitivity of the thermal performance on energy pile walls. Moreover, we note that there exist very limited field testing and monitoring from energy pile walls for understanding the complex wall systems in real world. In this paper, the first part reports a case study of in-situ thermal response tests on a pilot energy soldier pile wall, believed to be a world first, at two different embedment depths. The second part employs a numerical study using finite element analysis to investigate the long-term performance of the energy pile wall and the sensitivity of the embedment depths to the performance of the walls. Appropriate boundary conditions were selected to carefully account for the underground structures in contact with the wall when utilizing numerical modelling.

* Corresponding author: narsilio@unimelb.edu.au 


\section{Thermal response tests}

In-situ thermal response testing (TRT) is a typical field test, initially developed specifically for borehole heat exchangers, that can estimate thermogeological parameters, including undisturbed ground temperature, GHE thermal resistance and ground thermal conductivity. The use of TRTs has been subsequently extended to energy piles, although it can result in higher costs and uncertainties [5]. The test normally uses electrical heating elements to heat fluid at a constant power and circulating it within the GHE pipe loops. The inlet and outlet fluid temperatures are recorded over time, as well as the flow rate and power consumption. The collected TRT data are normally interpreted by curve fitting a heat transfer model and back-calculating the effective thermogeological parameters. Several simple analytical models exist for interpreting borehole TRT data, as well as more advanced recently developed analytical and semi-analytical models. However, few TRT studies exist for the case of energy retaining walls, which may be because of the more complex construction phases and geometry of the walls, which can make the test execution and data interpretation considerably more difficult. Lee et al. [6] attempted

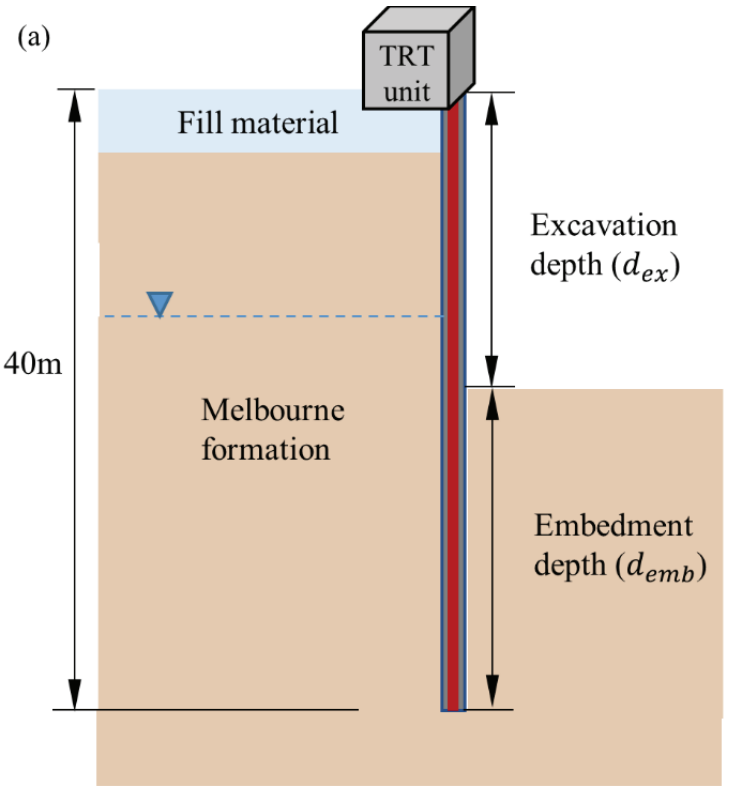

(b)

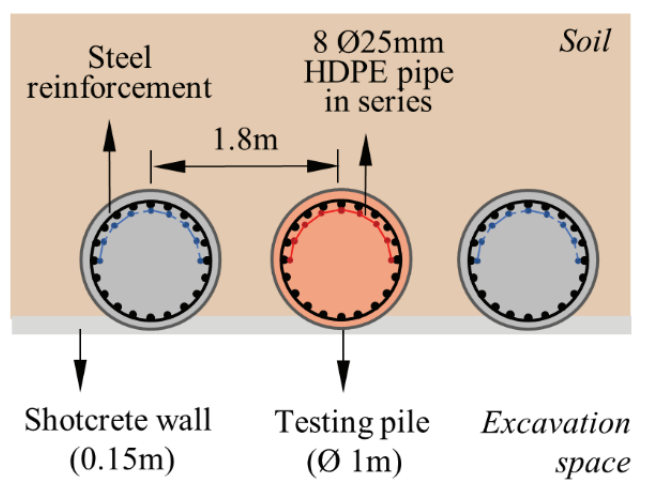

Table 1. Energy wall geometrical and thermal properties

\begin{tabular}{|c|c|c|c|}
\hline Parameters & Water & Concrete & Soil \\
\hline $\begin{array}{c}\text { Thermal } \\
\text { conductivity, } \\
\lambda, W /(m . K)\end{array}$ & 0.58 & 1.4 & 1.85 \\
\hline $\begin{array}{c}\text { Specific heat } \\
\text { capacity, } \\
C_{p}, J /(\mathrm{kg} . \mathrm{K})\end{array}$ & 4186 & 850 & 780 \\
\hline $\begin{array}{c}\text { Density, } \\
\rho, \mathrm{kg} / \mathrm{m}^{3}\end{array}$ & 1000 & 2373 & 2650 \\
\hline $\begin{array}{c}\text { Undisturbed } \\
\text { temperature, } \\
T,{ }^{\circ} \mathrm{C}\end{array}$ & 20 & - & 19.5 \\
\hline
\end{tabular}

multiple TRTs on two retaining wall panels, however, the data were not used for the determination of the ground thermal properties but instead to introduce a new terminology of relative heat exchange efficiency per unit pipe length to indirectly assess the energy performance. Zanni et.al. [7] proposed to perform TRTs on a recently built energy wall in Switzerland. The test execution details were briefly discussed, but the results are not yet available in literature. Overall, there is a lack of available TRT data and case studies for energy retaining walls, which can benefit the scientific and industry communities by providing insights and help our understanding of heat exchange within energy retaining walls.

\subsection{Test site set up and conditions}

Within this study, in-situ TRTs have been conducted on a well-documented pilot energy pile wall, believed to be the first of its kind in the world. The pile wall was constructed for a shaft to support a cavern excavation in the Melbourne CBD North Station. The preliminary field assessment of socket material was undertaken by drilling a $43 \mathrm{~m}$ borehole at the testing location. It was found that the geology consists of $5 \mathrm{~m}$ fill material overlaying Melbourne Formation siltstone and sandstone layers. The ground water table was found at approximately $15 \mathrm{~m}$ below ground surface with no evidence of significant groundwater flow. To be noted, dewatering occurs during construction to keep the station dry. Three adjacent bored piles have been thermally activated by embedding four Uloops of HDPE pipes in series, placed at equal separations within each pile. The geometrical arrangement of the pilot energy pile wall is illustrated in Fig. 1. A $75 \mathrm{~mm}$ concrete cover to edge of the pile is adopted for all pipes. Pile loops are connected in parallel through a thermally insulated manifold system installed above the ground as shown later in Fig. 2. The estimated values of the key thermal properties based on literature studies and in-situ testing analysed later in Section 3.2 are summarized in Table 1 and are used as inputs for numerical simulations undertaken within this work.

Fig. 1. Energy wall cross sectional view (a) and top view (b) 


\subsection{Field testing results}

Two in-situ TRTs have been conducted for a single energy pile at two different embedment depths, $30.8 \mathrm{~m}$ and $21 \mathrm{~m}$. The test set up is shown in Fig. 2 below.

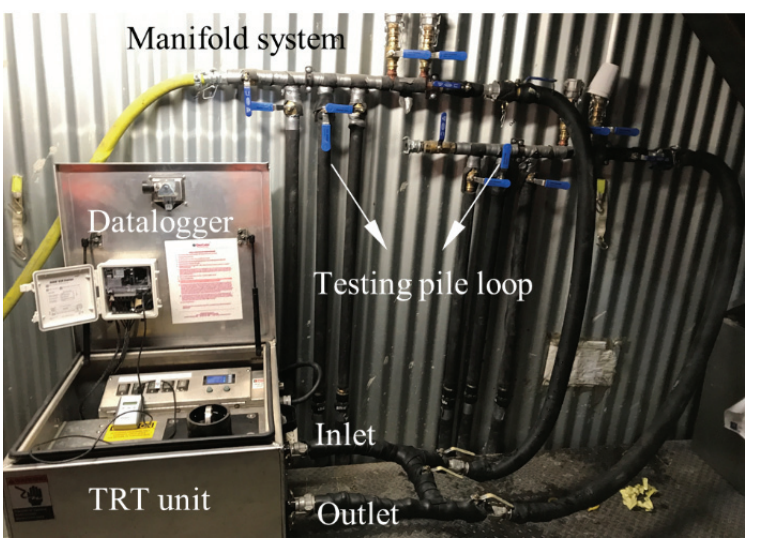

Fig. 2. In-situ TRTs set up with manifold system installed

The same testing unit was used for both TRTs, operated at an average flow rate of $8.4 \mathrm{~L} / \mathrm{min}$ with a constant power of $5.5 \mathrm{~kW}$ applied to the system for approximately 3 weeks. The second test commenced 45 days after the first test finished which allowed the ground to be restored to its undisturbed temperature conditions. TRT data were recorded every 2 minutes. Ambient temperatures inside the station shaft shed were measured over the testing period, since they can be influential to the test, especially for energy retaining walls.

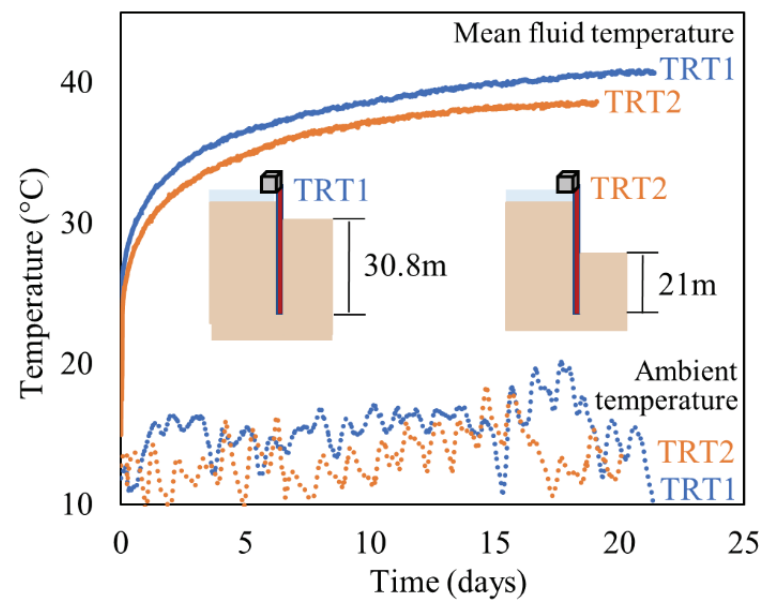

Fig. 3. In-situ TRTs mean fluid temperatures (solid lines) with measured ambient temperatures in the excavation space (dash lines)

Fig. 3 shows the mean fluid temperatures (i.e. the average between inlet and outlet temperatures) as well as the measured ambient temperatures obtained during TRT 1 and TRT 2. Both TRT response curves look similar to those of a typical borehole TRT, with the mean fluid temperatures increasing sharply at the beginning, after which the increase significantly decreases. The fluid temperatures in TRT 2 were overall lower than those from the first TRT 1, which might suggest that a larger amount of heat was dissipated to the excavation space due to the larger surface area of the wall being exposed to the air. However, the ambient temperatures in the station shed during TRT 1 were also higher than TRT 2, which can also be causing the temperature difference. To provide further data and since field testing can be limited and difficult to control, numerical modelling is also utilised to investigate the effect of the embedment depth on the thermal performance of energy pile walls. The details of the numerical simulations are presented in Section 3.

\section{Numerical simulations}

\subsection{Overview}

A 3D finite element model developed by the University of Melbourne is employed in this study, using the finite element software package COMSOL Multiphysics to simulate and evaluate the thermal response of GSHP systems [8-9]. The model couples the governing equations of heat transfer (energy balance) and fluid flow (momentum and continuity), and considers conductive heat transfer within the soil, the concrete and pipe walls and convection within the pipes due to the circulating fluid. More information and the complete governing equations can be found in [8-9].

In the scope of this study, the deep excavated metro station shaft is used as a case study for the modelling, focusing on energy pile walls, as seen in Fig. 4. Two different numerical models are utilised to account for different conditions, one simulating the TRTs on the single pile during excavation and the second assessing the long-term performance of the energy pile wall (all piles thermally activated). The geometry and configurations of the model is based on features of the energy wall, simulating a single activated pile for TRT and an infinitely long pile wall for long-term performance. For both cases, the soil is assumed homogeneous and isotropic for simplicity. Appropriate thermal boundary conditions are carefully selected to ensure realistic modelling of the system and thus results on the energy performance.

The first model, used to simulate the TRT case study, applies the measured ambient temperatures obtained during in-situ TRTs at the excavation surfaces and the top boundary to capture realistic field-testing conditions. A constant farfield temperature of $19.5^{\circ} \mathrm{C}$, which is the annual average undisturbed ground temperature in Melbourne CBD [10] is assigned as the thermal boundary condition at all other boundaries of the model, expecting that the heat transfer from the GHE does not affect these boundaries. The model dimension in $\mathrm{x}$ direction is set to be $20 \mathrm{~m}$ in line with the boundary conditions. A constant volumetric flow rate of $8.4 \mathrm{~L} / \mathrm{min}$ is applied in the entire length of the pipes for both tests. The inlet temperatures measured from the field tests in 6-minute time steps are used as inputs to the numerical model, which can then compute the outlet temperatures. The model is firstly used to reproduce TRT 1 and back-calculate pile and ground thermal conductivities. To ensure that it is capable of accurately representing the heat transfer process occurring 
in the energy pile wall, the model is then also tested against the full-scale field data from TRT 2 .

The second model is used to assess the long-term performance of the energy pile wall. Thermal insulation is adopted for the induced excavation space in front of the wall. This is considered as a safer approach in terms of operational limits of heat pumps [4] and imposing minimum effect to the thermal comfort within the station in real cases. The model width in the $\mathrm{x}$ direction is set to be $1.8 \mathrm{~m}$ (the centre-to-centre spacing between the piles). Symmetry is applied in zy plane on both sides of the model, which assumes the energy pile wall extends indefinitely along the $\mathrm{x}$-axis, which can be a conservative assumption. In addition, the farfield temperatures are assigned at the far end surfaces of the model. A constant operational volumetric flow rate of $5.5 \mathrm{~L} / \mathrm{min}$ is applied over the simulation time. In the first long-term analysis, the model is used to simulate the thermal performance of the energy pile walls over 25 years. In this case, the embedment depth is kept at $5 \mathrm{~m}$ which aligns with the operational design of the station for the entire analysis. A second long-term analysis focuses on investigating the effect of embedment depth on the long-term performance of the energy pile wall considering a range of ground thermal conductivities.

When assessing the long-term performance of GSHP systems, the thermal load distribution (how much heating/cooling the system can provide) plays a significant role and should be carefully considered in the system design process. For this study, a relatively balanced thermal load distribution is utilised, as it is considered the most ideal case and significantly benefits the systems' efficiency compared to an unbalanced one. A balanced load can be achieved by utilising hybrid systems (i.e. in combination with other auxiliary systems) or district systems (i.e. in combination of opposite load thermal patterns), more details on which can be found at $[4,12]$.

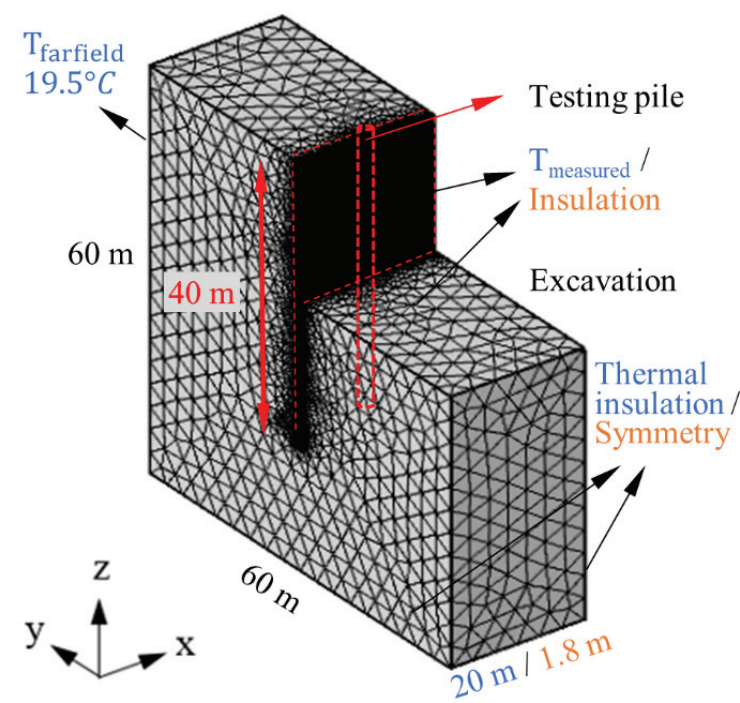

Fig. 4. Geometrical and applied thermal boundaries of the numerical models (blue for TRTs simulations, orange for longterm simulations)

\subsection{Parameter estimation and model validation}

The first numerical model introduced in Section 3.1 is validated against the field-testing results from the TRTs, determining the ground and concrete thermal parameters by fitting the data to the in-situ TRT 1 dataset. Fig. 5 shows the TRTs data obtained numerically compared to the field-testing data. The root-mean-square error (RMSE) of the residuals and the coefficient of determination $\left(\mathrm{R}^{2}\right)$ are computed in evaluating the goodness of fit of the numerical model. As it can be seen, the mean fluid temperatures in TRT 1 match well between numerical modelling and field testing when applying a ground thermal conductivity of $1.85 \mathrm{~W} /(\mathrm{m} . \mathrm{K})$ and a concrete thermal conductivity of $1.4 \mathrm{~W} /(\mathrm{m} . \mathrm{K})$. These estimated values were then adopted in TRT 2 , where a similar degree of agreement between the numerical modelling and fielding testing results is observed. These results provide confidence in the numerical modelling in addition to the expected values for the ground and concrete thermal conductivity which can then be used in the long-term performance assessment in Section 3.3. These values are also close to the value reported in the literatures $[5,11]$.

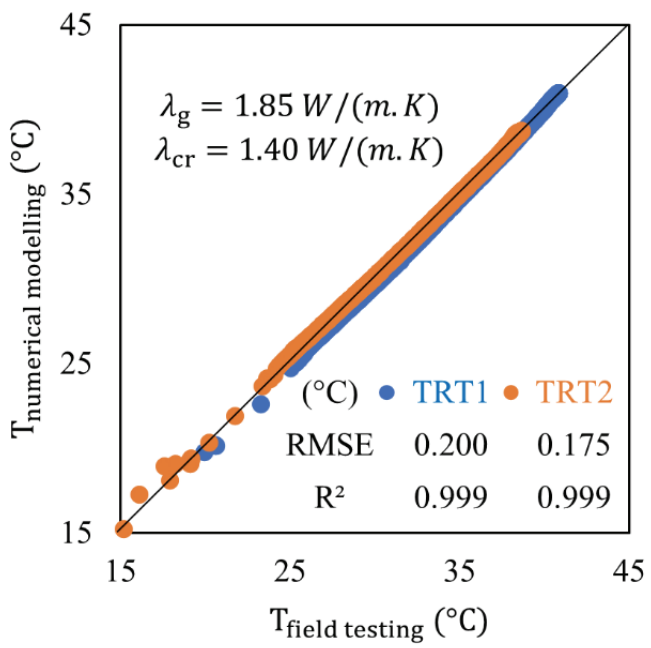

Fig. 5. Parameter estimation and validation results

\subsection{Long-term performance of the energy retaining wall}

For the assessment of the long-term thermal performance of the energy pile wall, the fluid temperatures within the pipes have to be maintained within reasonable operational limits of a typical heat pump (i.e. $-5^{\circ} \mathrm{C}$ to $40^{\circ} \mathrm{C}$ ). Antifreeze solution is needed for below $0^{\circ} \mathrm{C}$. In this study, the mean fluid temperature (the average of inlet and outlet temperatures) is employed for predicting the thermal performance of the energy pile wall over 25 years (a typical design lifetime of GSHP systems) and the maximum thermal potential of the wall was determined such that the maximum or minimum mean fluid temperature would be within these limits. 
For this study, the thermal load that the energy wall system is designed to provide is presented in Fig. . The predicted thermal performance over 25 years is shown in Fig. , the mean fluid temperatures fluctuate between $-3{ }^{\circ} \mathrm{C}$ and $35^{\circ} \mathrm{C}$ for the simulation periods. This range is within acceptable limits for GSHP operation, suggests that the system is capable to meet the designed thermal load. For this case study, if a total of 68 piles in the energy wall systems are all thermally activated, this will be equivalent to satisfy both the demand of a typical metro station and partial heating demand of several surrounding buildings. It is also worth to note that the variation between years is very minor, suggesting minimal heat accumulation in the ground, which can reduce the operational efficiency of the heat pumps leading to the system operating successfully for longer.

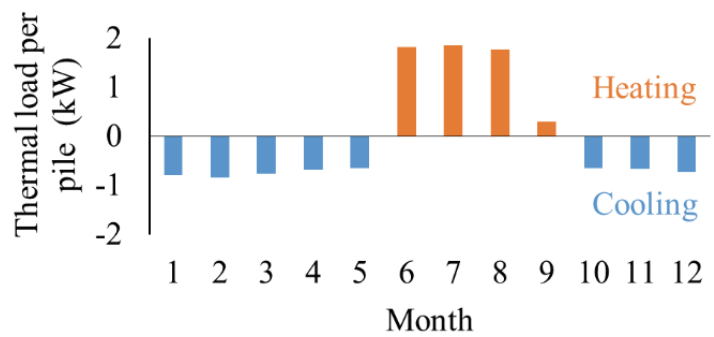

Fig. 6. The design thermal load for a single pile

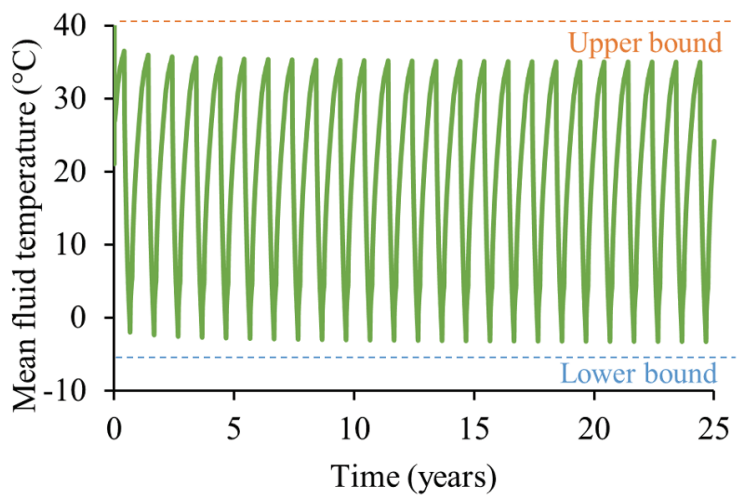

Fig. 7. Predicted thermal performance over 25 years in terms of the mean fluid temperatures

\subsection{Effect of embedment depth}

In this analysis, the embedment depth is varied while the entire depth of the retaining wall remains constant at $40 \mathrm{~m}$. Although the geothermal design would unlikely be able to affect the structural design (and thus such as the value of embedment depth) in real practice, it provides insights on the applicability of energy pile walls compared to energy piles, as well as the potential impact of different geometries to energy pile walls.

The thermal load demand shown in Fig. was adopted throughout the whole analysis. A summary the results can be seen in Fig. 8, showing the maximum average fluid temperature at the end of five years of operation. Five different values of the embedment depth, varied from extremes $40 \mathrm{~m}$ (i.e., effectively an energy pile) to $0 \mathrm{~m}$ (pure wall), are applied to three different ground thermal conductivities which covers the typical range for soils. As it can be seen, increasing the embedment depth, reduces the maximum fluid temperatures by between 5 to 9 degrees, and the impact for an equal change in depth is not constant but gradually increases with a deeper excavation. This trend is expected, since the thermal performance of an energy pile wall benefits from a larger contact area with the ground and hence greater heat storage.

However, the considerably large temperature difference implies a significant impact of the embedment depth considering a large infrastructure project like the metro station. This is particularly evident when encountering soils with a low thermal conductivity, since the magnitude of temperature change resulting from varying the embedment depth is almost double for the low conductivity soil compared to the medium to high conductivity soils.

This analysis suggests that there is a relatively large thermal performance differential between energy piles and energy piles walls, implying that the available design approaches for energy piles should not be directly applied to energy wall design. Instead, it is possible these approaches could be adapted for energy wall design, by further exploring the relationship of the results between energy piles and energy pile walls.

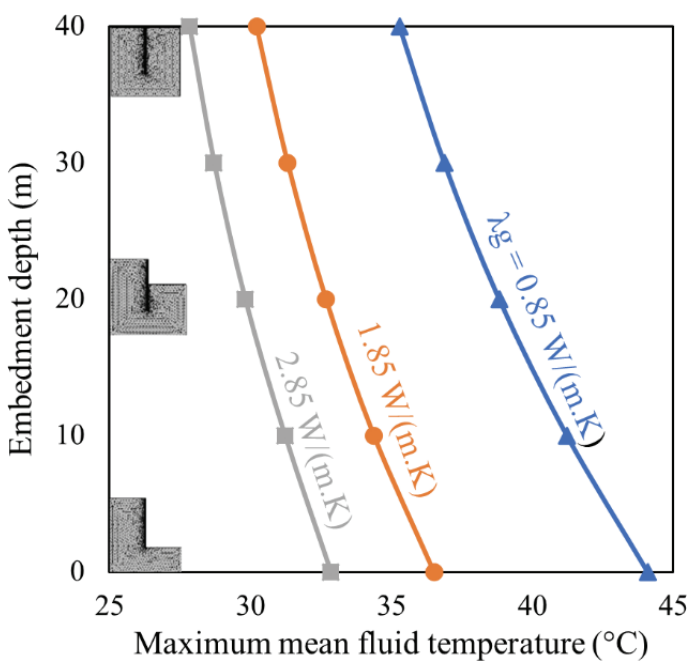

Fig. 8. The long-term effect of embedment depths

\section{Summary and conclusion}

This work investigates the thermal behaviour of the energy pile wall by a combination of field data and numerical modelling. A section of the soldier pile wall in the currently under-construction Melbourne CBD North metro station has been thermally activated and used as a case study to facilitate the investigation. The paper consists of two main parts, the first discussing field data and the second utilising numerical modelling.

The first part of this paper presents the results of two in-situ TRTs from the pilot energy pile wall. Both of the obtained TRT temperature response curves are similar to that expected from a typical borehole TRT. The response 
curves show that the TRT conducted at a shorter embedment depth reach lower mean fluid temperatures than those at a longer embedment depth, which might imply that a larger amount of thermal energy is transferred from the wall to the excavation space due to the larger contact area to the space. The testing data help understand the heating response of energy pile walls and serve as important data assets for verification of numerical models.

The second part of this paper presents a numerical study that focuses on the long-term performance of the energy pile wall with the use of a validated numerical model. Initially, it is shown that the simulated energy pile wall is able to supply the designed thermal load over 25 years comfortably, suggesting that the suitability of energy pile walls for space heating and cooling under the right conditions. Moreover, the simulation results conclude that increasing the embedment depth, cases a decrease in the maximum mean fluid temperature, a trend which is not constant with the depth but gradually increases with deeper excavation. It is also found that the magnitude of the temperature change resulting from varying the embedment depth is more significant when the soil surrounding the wall has relatively low conductivity. Overall, it is evident that the length of the embedment depth (including the presence of excavation space), can have a significant effect on the long-term performance of energy walls. This work suggests that further exploring the relationship between the embedment depth and the thermal performance, could lead to new approaches to energy wall design, which utilise available energy pile design approaches and adapt them based on this relationship.

Overall, this pilot project provides both insights, learnings and data that can contribute towards the further understanding of energy piled walls. The more the scientific community and industry understand the thermal behaviour and performance of these structures, the more information can exist, and tools can be developed for their design, testing and construction process, which can lead to a more sustainable future.

The authors gratefully acknowledge the continuous financial and technical supports by The John Holland Group (Early Works), The Cross Yarra Partnership, and Porous Media Research Laboratory at The University of Melbourne for carrying out the pilot energy wall project.

\section{References}

1. Q. Lu, G.A. Narsilio, Cost Effectiveness of Energy Piles in Residential Dwellings in Australia, Current Trends in Civil \& Structure Engineering. 3(3), CTCSE.MS.ID.000564, (2019).

2. S. Park, C. Sung, K. Jung, B. Sohn, A. Chauchois, H. Choi, Constructability and heat exchange efficiency of large diameter cast-in-place energy piles with various configurations of heat exchange pipe, Applied Thermal Engineering, 90, 1061-1071, (2015).

3. K. Sekine, R. Ooka, M. Yokoi, Y. Shiba, S. Hwang, ASHRAE transactions, 113(1), 741-753, (2007).

4. N. Makasis, G.A. Narsilio, A. Bidarmaghz, I.W. Johnston, Y. Zhong, Computers and Geotechnics, 120, 103399, (2020).

5. L. Jensen-Page, F. Loveridge, G.A. Narsilio, Thermal response testing of large diameter energy piles, Energies, 12, (2019).

6. S. Lee, S. Park, M. Kang, H. Choi, Field Experiments to Evaluate Thermal Performance of Energy Slabs with Different Installation Conditions, Applied Sciences, 8, (2018).

7. J. Zannin, A. Ferrari, M. Pousse, L. Laloui, Thermal design and full-scale thermal response test on Energy Walls, Web of conferences, 92, (2019).

8. A. Bidarmaghz, G.A. Narsilio, I.W. Johnston, Numerical modelling of ground loop configurations for direct geothermal applications, Australian Geomechanics Journal, 47, (2012).

9. N. Makasis, G.A. Narsilio, A. Bidarmaghz, I.W. Johnston, Y. Zhong, The importance of boundary conditions on the modelling of energy retaining walls, Computers and Geotechnics, 100, (2018).

10. O. Mikhaylova, I.W. Johnston, G.A. Narsilio, A.V. Kivi, R.A. Aditya, G. Noonan, Performance of Borehole Ground Heat Exchangers under Thermal Loads from a School Building: Full-scale Experiment in Melbourne, Australia, Proceedings World Geothermal Congress, 19-25, (2015).

11. D. Barry-Macaulay, A. Bouazza, R.M. Singh, B. Wang, P.G. Ranjith, Thermal conductivity of soils and rocks from the Melbourne (Australia) region, Engineering Geology, 164, (2013).

12. Aditya, R. A., \& Narsilio, A. G. (N.A). District ground source heat pump systems for temperate climatic conditions. Submitted to Applied Thermal Engineering. 